Brit. J. prev. soc. Med. (1976), 30, 197-202

\title{
Degree of physical handicap, education, and occupation of 51 adults with spina bifida
}

\author{
K. M. LAURENCE AND ANN BERESFORD \\ Department of Child Health, Welsh National School of Medicine, Heath Park, Cardiff
}

\begin{abstract}
Laurence, K. M. and Beresford, A. (1976). British Journal of Preventive and Social Medicine, 30, 197-202. Degree of physical handicap, education, and occupation of 51 adults with spina bifida. 51 adults with spina bifida, aged between 18 and 56 years, resident in South Wales, were interviewed in their home. Although only four had obvious hydrocephalus, one-third of them were severely handicapped and a further $40 \%$ had moderate handicap. Over half of them had had their secondary education in a normal school, with the remainder having special schooling or home tuition. Seventy per cent of the series was in normal, full-time occupation, including half those severely handicapped. Those in work were largely in managerial/technical, clerical, and light manual occupations. It is concluded that extended schooling for those individuals with special vocational guidance and training, followed by special job placement, would help to integrate them into the community. These patients show that, in the absence of mental retardation, even severe physical handicap is no bar to normal occupation and that paralysis and incontinence alone are probably not valid selection factors for or against 'aggressive' treatment for spina bifida.
\end{abstract}

Before 1960 most children with spina bifida cystica and related conditions did not survive long, but with improved standards of medical care and modern surgical techniques a sizeable cohort of patients, many severely handicapped, have survived to school ages and will shortly be facing adult life; some will be seeking employment.

Little has been written about the reality of life for the adult spina bifida survivor; the study by Evans, Hickman, and Carter (1975) concentrated chiefly on the handicap and the social status of patients seen in London hospitals. We here report some of the problems that survivors in South Wales have found in training and in the daily exercise of a steady occupation.

\section{Patients AND Methods}

Fifty-nine men and women between the ages of 18 and 56 years, born and still resident in South Wales, living in the community and diagnosed as having one of the major dysraphic neural tube malformations were ascertained. The medical notes were traced to determine the type of lesion involved and the family doctor was consulted before each subject was asked to participate. The family doctors of two patients advised against the visit for fear of upsetting the family, the doctor of four more failed to respond to repeated inquiries, and two further individuals themselves refused, leaving 51 patients in the investigation (28 men and 23 women), see Table I. Primary ascertainment of $\mathbf{3 0}$ of these patients was through the diagnostic index kept at the Cardiff Royal Infirmary since 1920 , the only centre providing specialist paediatric and neurosurgical services at that time. It was found from the records of the Hospital for Sick Children, Great Ormond Street, that there were six patients from Wales who had been referred there for treatment. Seven patients all under the age of 30 years were found through the local authority lists of children attending schools for the physically handicapped. Four were referred to us by general practitioners who knew our interest in the problem, the names of two were given to us by the Spina Bifida Parents' Association, and two were ascertained through their similarly affected offspring. Thirty-five of the patients were ascertained from more than one source. 
TABLE I

AGE AND DISABILITY GRADE

\begin{tabular}{|c|c|c|c|c|c|}
\hline \multirow{3}{*}{ 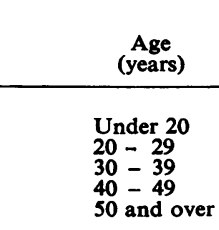 } & \multicolumn{3}{|c|}{ Degree of Physical Handicap } & \multirow{2}{*}{\multicolumn{2}{|c|}{ Total }} \\
\hline & Minimal & Moderate & Severe & & \\
\hline & $\begin{array}{rr}3 & (1) \\
5 & (4) \\
5 & (2) \\
2 & -(0)\end{array}$ & $\begin{array}{rr}4 & (1) \\
8 & (3) \\
5 & (4) \\
3 & (3)\end{array}$ & $\begin{array}{rr}4 & (0) \\
5 & (1) \\
5 & (3) \\
2 & -(1)\end{array}$ & $\begin{array}{r}11 \\
18 \\
15 \\
3 \\
4\end{array}$ & $\begin{array}{l}\text { (2) } \\
(8) \\
(9) \\
(3) \\
(1)\end{array}$ \\
\hline Total & $15 \quad(7)$ & $20 \quad$ (11) & $16 \quad(5)$ & 51 & (23) \\
\hline
\end{tabular}

Number of women is given in brackets

No attempt was made to achieve complete ascertainment of spina bifida patients over the age of 18 years as the aim of the investigation was to obtain a spectrum of the problems encountered and to see whether these were overcome, rather than the distribution of the problems. Forty-eight of the subjects came from Glamorgan and Gwent, with the remaining three from Dyfed. Of the seven cases over the age of 40, five came from the Cardiff area.

Using the survival figures obtained from the follow-up study of untreated spina bifida patients born between 1956 and 1962 in South Wales of Laurence and Tew (1971) and making allowance for both the mobility of the patients and the reduced expectation of life, we have made an estimate of the lower limit of the completeness of the sample of the spina bifida patients resident in Glamorgan and Gwent. It seems likely that at least $75 \%$ of those under the age of 20 were ascertained, only about $30 \%$ of those between 20 and 40 years, but a smaller proportion of those over $\mathbf{4 0}$ years old. We think it probable that as these patients grew up before the antibiotic era they will have tended to succumb to intracranial infection and that the number of unreported survivors will be less than indicated. It is probable that some of those 'missing' were mildly affected and had not sought help or had been referred to other centres. It is known that at least eight severely mentally retarded and physically handicapped individuals over the age of 18 years are at present in the long-stay institutions in Glamorgan and Gwent.

Each of the 51 patients was visited in his home by a social worker (nearly all by $\mathrm{AB}$ ) and a semistructured interview was conducted, using a questionnaire concentrating on educational and employment experience but also dealing with management of social, emotional, and physical problems. The hospital case notes were consulted and were assessed by KML. The degree of physical disability in these patients, derived from their own reports, hospital notes, and the interviewers' observations, fell into three broad grades according to function, as in previous studies (Laurence and Tew, 1971; Laurence, 1974):

The minimally handicapped, some of whom had some physical deformity, a squint, slight imbalancळ or slight limp. Some of these adults wore surgical $\bar{P}$ supports or boots, but were able to get abous without aids and were totally continent, excep $\$$ under severe stress.

The moderately handicapped often had quite severe deformity of the spine or feet and quite marked paralysis of the legs requiring braces, some instances extending to the waist, in addition to a walking stick or crutches for ambulation. Three patients had artificial legs. Some of them were able to manage only relatively short distances. They were either only partially continent, usually with incontinence at night, or remained dry with appliances or a successful diversion operation.

The severe group included those who were very severely paralysed and could not ambulate except perhaps for a few steps and were virtually chairbound, or they were totally incontinent without any diversion operation. Some were both chairbound and incontinent. One was bedridden

\section{RESULTS}

\section{Physical Handicap and Mental Status}

Almost one-third of the series were severely handicapped and mostly chairbound and incontinent; less than one-half of the remainder were relatively unscathed. As might be expected, 12 of the 30 myeloceles were severely handicapped and only one was minimally affected. Nine of the 11 meningoceles were unscathed, but the other two appeared to develop handicap after cosmetic surgery in childhood. Two of the four encephaloceles had no physical handicap but the other two were spastic and 
incontinent, one largely as a result of severe mental retardation. Of the six complicated spina bifida occulta, three had various degrees of incontinence and paralysis (Table II). Nearly all of these survivors had either entirely escaped hydrocephalus, or the condition had become arrested spontaneously before it had progressed far. In only four was there any significant head enlargement. The intelligence levels in most patients appeared within normal limits, although no formal assessment has been carried out. Only four patients seemed severely mentally retarded including three of the four encephaloceles, but not any of the four who were obviously hydrocephalic. In addition, there were seven who seemed educationally subnormal, probably partly because of the incomplete schooling they had received.

\section{EDUCATION}

There was a wide variation in schooling. Primary education had usually started at the local school, sometimes beginning late, often interrupted by frequent hospital admissions and illnesses, and in some cases by periods of home tuition as well. Secondary education, on the other hand, had been at the local ordinary school exclusively for 28 and predominantly for a further three. Fourteen others had gone to a special school for the physically handicapped, in most instances as boarders. Six had had all their secondary education in the form of home tuition. For five patients there had been no schooling for more than 12 months for reasons other than medical attention. Two had had no provision at all under the age of 10 years and one girl had not received any education until the age of $14 \frac{1}{2}$ years, and then only in the form of home tuition.

Many felt that their schooling had been disrupted by the necessity for medical and surgical attention and considered their education to be somewhat incomplete for that reason alone and would have liked a longer period of schooling. However, 28 were reasonably satisfied with their educational experience and 12, although they had some criticisms, felt that the overall provision was as good as they could have expected. On the other hand, a further 10 felt ill-served. Their comments included the narrowness of the curriculum and social isolation of home tuition and, in the special boarding schools, the lack of stimulus for the brighter pupils. Five, including the mentally retarded, had left school capable of only limited reading and writing, but 16 had achieved CSE or GCE O-level attainments, and three had reached A-level studies, one in a college of further education, one was about to go to a college of education, and one had an option of taking up a university place.

\section{Vocational Guidance and Training}

Eleven alone out of the whole group had had training, assessment, or rehabilitation through a government-sponsored scheme. Of these only five had had meaningful vocational assessment and training and all those had found work quickly and directly as a result of that training, and had worked regularly ever since (two as clerks, two as telephonists, and one as a telephone service engineer). Assessment and rehabilitation without vocational training were not found particularly helpful. Of the four who undertook this, one remained unemployed, one is now in sheltered work, and two are now in open employment, but entirely due to their own efforts and perseverance. Two more were inappropriately offered help through statutory provision; one, a woman, had been sent on a course for the partially-sighted but found to be ineligible, and a second woman who took a needlework course instigated by the Department of Employment which had stimulated interest and widened her experience had been prevented by ill health from completing it, let alone taking full-time employment.

In addition to these, two had taken a training course at their own expense at a secretarial college, which has led to full-time, open, regular employment.

TABLE II

TYPE OF LESION OF ADULT SURVIVORS WITH SPINA BIFIDA

\begin{tabular}{|c|c|c|c|c|}
\hline \multirow{2}{*}{ Type of Lesion } & \multicolumn{3}{|c|}{ Degree of Physical Handicap } & \multirow{2}{*}{ Total } \\
\hline & Minimal & Moderate & Severe & \\
\hline $\begin{array}{l}\text { Complicated SBO } \\
\text { Meningocele } \\
\text { Myelocele } \\
\text { Encephalocele }\end{array}$ & $\begin{array}{ll}3 & (2) \\
9 & (3) \\
1 & (1) \\
2 & (1)\end{array}$ & $\begin{array}{rr}1 & (-) \\
17 & (-) \\
1 & (1)\end{array}$ & $\begin{array}{rr}2 & (-) \\
1 & (-5) \\
1 & (-)\end{array}$ & $\begin{array}{rr}6 & (2) \\
11 & (3) \\
30 & (16) \\
4 & (2)\end{array}$ \\
\hline Total & (7) & $20 \quad$ (11) & $16 \quad(5)$ & $51 \quad(23)$ \\
\hline
\end{tabular}


Twenty of the series had known many job changes, as well as lengthy periods of unemployment, mostly at the outset of their working life or later as a result of deterioration in their physical condition. Only when unemployment had become critical did they learn of vocational training schemes provided through the Department of Employment.

\section{OCCuPation}

Thirty-six were either completely self-supporting in ordinary competitive employment, carrying out the normal duties of housewife or mother or in normal full-time grant-aided studies. This group included two temporarily off sick, who were due shortly to return to ordinary open work, and eight of the 16 graded as severely handicapped were leading normal lives in that six were in open full-time work, one in full-time studies, and one was a housewife coping unsupported. One completely chairbound young man with bladder incontinence worked full-time as a telex operator. Another chairbound, unoperated, partially incontinent woman had worked for 12 years in an office. A third person with an artificial leg, hip dislocation and incomplete bladder control, able to walk only with a stick and dependent upon an invalid car, worked regularly as a telephonist. All but two of those in paid, open employment were in light manual, clerical or managerial/technical jobs (Tables III and IV). The two exceptions were a moderately disabled man, working as a labourer because he was untrained for work more suited to his capacities, and a very minimally affected man working as a miner.

The remaining 15 presented a very different picture. They included all those who are mentally $?$ retarded and two in whom there has been recent $\overrightarrow{\vec{F}}$ deterioration. Three were in sheltered employment, $\frac{\text { ? }}{+}$ such as Remploy or Workshops for the Blind, and therefore only partially self-supporting. Three more, $\frac{\bar{\sigma}}{\bar{w}}$ two severely retarded and one very handicapped, $\frac{\vec{\sigma}}{\widetilde{ }}$ were 'occupied' in local authority day centres, while $\varrho$ one who was relatively unscathed but maladjusted, was newly engaged in craft work at home which he $\overrightarrow{0}$ hoped would eventually become remunerative. Of the eight totally unemployed, two had never worked $\vec{\omega}$ because of their severe disability. A further two were recently out of work because of deterioration, one $\stackrel{乛}{?}$ because of an unsuccessful attempt at surgery for the spinal lesion and the other because of rapidly progressive disseminated sclerosis. The remaining four, all severely handicapped school-leavers, $\varphi$ consisted of one who was trying to obtain placemento in a sheltered workshop, one seeking work, and twe who seemed completely without motivation.

\section{Discussion}

As all the patients in this series were born before 1956, well before the introduction of the 'aggressive $\overrightarrow{0}$ approach to spina bifida, few had immediate closure of the spinal lesion and none had had effective surgery for progressive hydrocephalus. This second factor almost certainly accounts for the absence of

TABLE III

OCCUPATION OF ADULTS WITH SPINA BIFIDA

\begin{tabular}{|c|c|c|c|c|c|c|c|}
\hline \multirow{3}{*}{$\begin{array}{c}\text { Degree of } \\
\text { Physical Handicap }\end{array}$} & \multicolumn{3}{|c|}{ In Normal Occupation } & \multicolumn{3}{|c|}{ Not in Normal Occupation } & \multirow{3}{*}{ Total } \\
\hline & \multirow{2}{*}{$\begin{array}{c}\text { Open } \\
\text { Employment }\end{array}$} & \multirow[b]{2}{*}{ Housewives } & \multirow{2}{*}{$\begin{array}{l}\text { Full-time } \\
\text { Student }\end{array}$} & \multicolumn{2}{|c|}{ Occupied } & \multirow[b]{2}{*}{ Unemployed } & \\
\hline & & & & Paid & Unpaid & & \\
\hline $\begin{array}{l}\text { Minimal } \\
\text { Moderate } \\
\text { Severe }\end{array}$ & $\begin{array}{r}8 \\
14 \\
6\end{array}$ & $\begin{array}{l}3 \\
2 \\
1\end{array}$ & $\frac{1}{1}$ & $\begin{array}{l}1 \\
1 \\
1\end{array}$ & $\begin{array}{l}1 \\
2 \\
1\end{array}$ & $\begin{array}{l}1 \\
1 \\
6\end{array}$ & $\begin{array}{l}15 \\
20 \\
16\end{array}$ \\
\hline Total & 28 & 6 & 2 & 3 & 4 & 8 & 51 \\
\hline
\end{tabular}

TABLE IV

TYPE OF PAID EMPLOYMENT OF ADULTS WITH SPINA BIFIDA

\begin{tabular}{|c|c|c|c|c|c|c|c|}
\hline \multirow{3}{*}{ Type of Employment } & \multicolumn{6}{|c|}{ Degree of Physical Handicap } & \multirow{3}{*}{$\frac{\text { Total }}{31}$} \\
\hline & \multicolumn{3}{|c|}{ Men } & \multicolumn{3}{|c|}{ Women } & \\
\hline & Minimal & Moderate & Severe & Minimal & Moderate & Severe & \\
\hline $\begin{array}{l}\text { Managerial/technical } \\
\text { Clerical } \\
\text { Light manual } \\
\text { Heavy manual }\end{array}$ & $\begin{array}{l}2 \\
2 \\
1\end{array}$ & $\begin{array}{l}3 \\
2 \\
1 \\
1\end{array}$ & $\begin{array}{l}-2 \\
3 \\
\end{array}$ & $\begin{array}{l}1 \\
\mathbf{1} \\
\mathbf{2} \\
\end{array}$ & $\begin{array}{r}-6 \\
2 \\
\end{array}$ & $\begin{array}{l}1 \\
-\end{array}$ & $\begin{array}{r}7 \\
14 \\
8 \\
2\end{array}$ \\
\hline
\end{tabular}


any significant hydrocephalus in most of these survivors and the relative intellectual normality, as in the series of Evans et al. (1975). Over two-thirds were at least moderately physically handicapped.

Spina bifida patients with minimal physical handicap, who made up only one-third of our cases, had few special work problems, unless they had complications such as mental retardation. However, those with moderate or severe handicap certainly did need help at the very least in the form of information and timely advice from a careers advisor. In many cases specific training and special placement would have helped to enable them eventually to play their full part in the community. Nonetheless, in spite of only variable help, over $70 \%$ of the total group are in ordinary open employment, coping unsupported with ordinary living or in higher education. Many do so through a remarkable degree of courage and determination and strength of personality, regarded by Greaves (1969) to be the most important factor leading to employment and retention of employment. However, in addition to personality, an intact and trained intellect is a vital qualification to enable handicapped spina bifida patients to carry out the managerial, clerical, technical, and skilled light manual work for which they seem to be most suited. Work involving less skill in such persons seems to lead to dissatisfaction, frequent job changes, and eventually idleness (Ferguson and Kerr, 1960).

Schooling for our sample took place over a span of four decades, in the course of which considerable changes in our education policy had taken place. In recent years especially, the importance of special educational help for the handicapped has been appreciated and much effort and resource is now being expended in this area (Tuckey, Parfitt, and Tudsey, 1973). Although the desirability of starting education for handicapped children at or soon after two years has been recognized and legislated for, this is a provision (Education Act, 1944) which has not yet been implemented to any extent. Extension of schooling, so often interrupted for medical reasons, beyond the statutory 16 years for those who might benefit, was considered a desirable measure by many of this sample. This would certainly be a valuable provision, especially if vocational training after careful assessment and guidance were made a part of it, as these physically handicapped children seem to be most suited for occupations requiring at least some academic attainments. In any case an extension of the Careers Advisory Service combined with more training facilities followed by suitable work opportunities, seem clearly to be essential to help to place those in suitable occupation who now find great difficulty.
The patients in this series illustrate that physical handicap alone, even when severe, is no bar to full-time normal occupation. Lack of confidence and lack of any readily marketable skill, which may be the results of disrupted or incomplete schooling and vocational training were often the greater obstacles to be overcome. The problems of incontinence, often a great embarrassment to the young schoolchild, could be more readily borne in the adult by careful management, personal hygiene, and appropriate aids. Problems of mobility, on the other hand, tended to become greater in adult life for they move from specially designed school buildings to the open community, which even today in its public buildings makes few concessions to the handicapped.

There are two major groups of spina bifida survivors to whom this study may be relevant. The cohort born 1960-72, most of whom have been aggressively treated, who are now passing through the schools will as a group present very different and much more formidable problems than the older survivors. Not only will a greater proportion have more severe paralysis, incontinence, and deformity but most will have at least some intellectual deficit (Laurence, 1974; Tew and Laurence, 1975). In addition, resulting from hydrocephalus and its complications and meningitis, a significant number will be from broken homes (Tew, Payne, and Laurence, 1976). The other group is the cohort born since 1973 after reappraisal of the long-term results of treatment in Sheffield (Lorber, 1972), which has led to a more discriminating attitude towards the condition, together with less surgical intervention in the worst affected infants. It is likely in future fewer survivors will have gross physical handicap and mental retardation and that they may well grow up to be more akin to our adult survivors, and therefore have the problems of management of life and occupation that the patients in this series presented.

In conclusion, any methods of selection of spina bifida infants for 'aggressive' treatment should concentrate on identifying for exclusion those cases who will turn out to be brain-damaged because of cerebral malformation or abnormality, intracranial infection or hydrocephalus, but paralysis and incontinence (Lorber, 1972) ought not by itself be a major deciding factor.

We wish to thank the South Wales Association for Spina Bifida and Hydrocephalus for their financial support, the spina bifida patients for their help and co operation, and Mrs P. Rowlands, who carried out some of the initial interviews.

Requests for reprints: Dr K. M. Laurence, Department of Child Health, Welsh National School of Medicine, Heath Park. Cardiff. 


\section{REFERENCES}

Education ACT (1944), (7 Geo. VI), Section 34. HMSO, London.

Evans, F., Hickman, V., and Carter, C. O. (1975). Handicap and social status of adults with spina bifida. Brit. J. prev. soc. Med.. 28, 85.

Ferguson, T. and KerR, A. W. (1960). Handicapped Youth. Oxford University Press for Nuffield Foundation, Oxford.

Greaves, M. (1969). Work and Disability; Some Aspects of the Employment of Disabled Persons in Great Britain. Council for Rehabilitation of the Disabled, London.

LAURENCE, K. M. (1974). Effects of surgery for spina bifida cystica on survival and quality of life. Lancet, 1, 301. and Tew, B. J. (1971). Natural history of spina bifida cystica and cranium bifidum cysticum; the majo central nervous system malformations in South Wales? Part IV. Arch. Dis. Childh., 46, 328.

LORBER, J. (1972). Spina bifida cystica. Results of treatment of 270 consecutive patients with criteria for selection for the future. Arch. Dis. Childh., 47, 854은.

Tew, B. J. and LaURENCE, K. M. (1975). The effects of hydrocephalus on intelligence, visual perception and school attainments. Develop. Med. Child Neurol., 17\% Suppl. 35, 129.

- Payne, H., and Laurence, K. M. (1976. Matrimonial stability following the birth of a child with spina bifida. (To be published).

TuCKey, L., Parfitt, J., and Tudsey, B. (1973)尺 Handicapped School Leavers: Their Further Education Training and Employment. National Federation foP Educational Research, Windsor. 